\title{
A Pilot Survey on Causes of Delay in Malaysian Construction Project
}

\author{
Norngainy Mohd Tawil ${ }^{1}$, Muhamad Azry Khoiry ${ }^{2}$, Noraini Hamzah ${ }^{3}$, Ishak Arshad ${ }^{4}$, Wan \\ Hamidon Wan Badaruzzaman ${ }^{5}$ \\ ${ }^{1}$ Department of Architecture, The National University of Malaysia, Malaysia \\ ${ }^{2,3,4,5}$ Department of Civil \& Structural Engineering, National University of Malaysia, Malaysia
}

\begin{abstract}
Construction delay is a common problem in the construction industry all over the world. Many researchers seeking the causes of delay in order to reduce the probability of delay to occur. Most researcher identified causes of delay in construction to reduce the possibility of construction project to continued delay. This study is to obtain the holistic delay categories base on Drewin Open Conversion System (DOCS) for the development of a theoretical framework delay and to get the most significant causes of delay in construction industries. There are three main factor of construction delay based on DOCS; input factor, internal factor and external factor. There are130 items on causes of delay and it is divided into 31 categories. This pilot survey is distributed to students and fresh graduates that have educational background in construction. The result shown the main factor that contributes to construction delay are mistakes during construction and unrealistic project durations.
\end{abstract}

\section{Introduction}

Engineering and management are the importance element to achieve success, said by the main donor of Maurice Lubbock Memorial Fund in Universiti Oxford. Those great ideas are the main factors to the European industry who led the world of engineering industries. This is proven by the achievement of world class construction projects, the London 2012 Olympic and Paralympics Games which is the largest sport project in Europe. The construction are worth multibillion pound said Howard Shiplee, the construction Manager for Olympic Delivery Authority (ODE) in his Maurice Lubbock Memorial Lectures 2012 [1].

To achieve a developed country status, construction industry plays an important role to realizing this aspiration. The construction industry in Malaysia has started before 1957 [2] and it has been a productive industry until now. Construction is a process that consists of the installation of the building and/or infrastructure development [3]. A construction project consists of multiple activities at one time [4]. In construction there are variety of unforeseen circumstances often occur and interfere with construction projects. The term "delay" is a matter or event that causes the extension of the period of time or delay to the activities in a construction project [5]. Delays are common issues in construction projects around the world [6].

Identification of the cause of delay is important to minimize the delays that occurred in construction work. The effect of delay will pressurized the contractors on the implementation of 
construction projects. When a project has experienced some delays, the contractor will accelerate or add provisions stipulated time [7]. Often times the issue of delay caught the attention by researcher from all over the world and it seem that the issue is endless. This research will discuss the development theoretical framework of delay in construction industries and the causes of delay to overcome the delay factor.

\section{Literature Review}

Various studies have produced research about construction delays around the world. The first is the comparative study, the causes of delay in construction management hospital in Libya and the United Kingdom [8]. Researchers use case studies as a method of identifying the causes of the delay in construction. This study categorizes the type of delay into primary and secondary category. Primary category consists of the delay caused by the management, financial and technical while the secondary category is a combination of two or more causes of the delay of the first category. As conclusion this study was performed to assess the extent of the challenge in the construction of the hospital building.

The seconds study is to identified the cause of delay based on the stages of construction, there are (i) feasibility studies and preliminary plans, (ii) the announcement and submission of the application, (iii) evaluation and selection, (iv) the negotiation and signing of the agreement, (v) design, (vi) construction (vii) operation and (viii) transfer [9]. The results of this study indicate a delay in the construction of built-operate-transfer contract is from the category of "negotiation and signing of the agreement" consisting of improper contract planning, debt and uncertainty about political issues and government.

The causes of delay from the problems that occur in the construction process can be sorted into four categories; owner related, contractor related, general problems and resource. All four categories representing the factor for reason of delay in construction development projects. Researchers noted to minimize delays in construction by the identification of the cause of the delay in depth [10].

The forth research is by Mahamid and Arabia [11], is about identification of delays in construction roads project in the West Bank, Palestine. Researchers noted that the delay not only affects the implementation process, but it would increase the cost and lessen the quality of the construction. A total of 45 causes of delay is stated and sorted into 5 categories; project management, consulting, finance and beyond. From the category stated, the researchers founded that the causes of the delay in financial group is listed as two of the top three main causes of delays [11] .

Finally Akogbe et. al. [12] they has identify the factors of delay in construction projects di Benin, a country located in West Africa. This study found that the delay is causes of financial problems, political and administration methods used by the country. The researcher list out 35 causes of delay in construction and divide it into five categories based on parties in the construction project; owners, consultants, architects, contractors and external [12].

The observation made from those six studies; help the researcher to categorize the cause of construction delay into several categories. There are by the implementer or parties of the construction project, construction process and stage of construction. It is found that there is no holistic and systematic source of framework for the classification of delay types in construction projects. Therefore, this study will propose a detailed framework for categorize the types of the construction delay. It is important to make the research more systematic and can be tested to describe the elements relationship in the research.

\section{Construction Delay Theoretical Framework}

A several studies are referred to collect the causes of delay in construction industries. It is load into the theoretical framework. For the framework purpose, this study applies the Drewin Open Conversion System (DOCS) as the basis of the theoretical framework. DOCS is a system that reflects the input and output of a construction activities [14]. The system introduced by Drewin (3) was used to describe the productivity of the construction process [15]. Synonym to the productivity is the 
production, it is often interpreted as the work done per unit of time [16]. Production can be increased by increasing one of the input factors and vice versa. Therefore it is important to relate the relationship between input factors and result in comparing productivity [17].

The DOCS was used in classifying the causes of delays in construction projects in this study. Generally DOCS illustrates typical construction system enables interoperability between a factor and the other factors. It is also shown the disturbance and feedback that occurs naturally in the construction processes. There are three main factors of delay; input factor, internal factor and external factor. This is a holistic theoretical framework as it is developed based on the process or situation in construction projects. From DOCS the researcher modified the framework to suit the causes of construction delay as shown in Figure 1. This framework was tested by combining the causes of the delay of a review written by $[9,11,12,13,14,19]$. Figure 3 shows the list causes of delay based on the category in accordance with the theoretical framework for the study of delay

Based on productivity framework there are three main factors of delay; input factor, internal factor and external factor [20]. Each of the factors are divided into to a few groups based on the specific criteria. Input factor is that element that needs to operate any process or system. These factors are the least factor of construction delay in this study. In the construction activities the element are financial, labors, materials and machineries. Second is internal factor, the inner parts or element in construction activities and it is the most critical factors of construction delay in this research. The activities include site management, monitoring, experience, shop drawing, pre-investigation, discrepancy, legislation, drawing, safety, variations, scheduling and controlling techniques, motivation, design, testing and inspection, quality, communication, decision making process, tendering, operation, management and administrative. Last but not least is the external factor, that can't be control by the parties in the construction. It always involved the third party and force majeure. The factors are site condition, weather economic condition, public and local authorities.

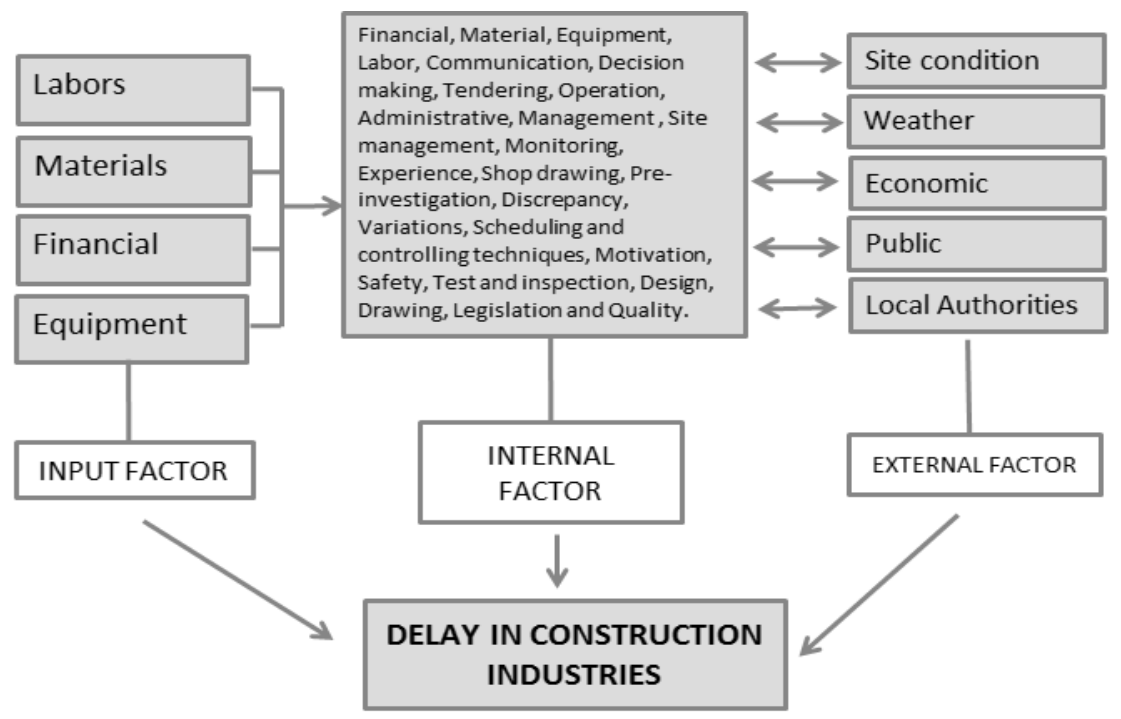

Figure 1: Simplified DOCS for causes of construction delay

\section{Research Methodology}

A pilot survey is important before a real survey will be done. This is to ensure the construction of the instrument or the questionnaires are valid, and indirectly reflect to the quality of the theoretical framework. Hundred sets of questionnaires have been distributed to students and fresh graduates from Department of Civil \& Structure Engineering, National University of Malaysia. This is to get their opinion on why delay happened Malaysia construction industries based on their study experience. Seventy nine has respond to the questionnaire ( $79 \%$ of survey responds). The questionnaires asked the 
respondent to state their level of agreement with each of the 130 causes of delay on a 5-point Likert scale $(1=$ strongly disagree to $5=$ strongly agree). Data were tabulated and analyzed using Rasch rating scale model.

\section{Result and Discussion}

The pilot survey research was conducted to civil engineering students and fresh graduates. Later the result were tabulated and run in Winstep, a Rasch Analysis software. The summary statistics of the result shown; the reliability provided by the instrument yields a Cronbach-alpha value of 0.97 which is in the excellent range of reliability. In addition, the person and item reliability values are 0.96 and 0.67 . The person reliability value is in a very good range, while the item reliability lies in the fair range. This indicates that the theoretical framework and survey instrument for measuring content validity is reliable. However the item spared is small due to the respondent are from the students and fresh graduates, they only judge by the theory perspective. A fair range of item reliability value due to the factor is in a very wide range, where it consists plenty of factors which have low quality to the research.

The PIDM in Figure 2 displays the distribution of the respondent on the left and the distribution of item agreement on the right according to item number, please refer code at Figure 4 . The most agreed-to items are items h2 (mistakes during construction) and $\mathrm{r} 2$ (unrealistic project durations), located at -0.71 logits, both are from the internal factor group, followed by $\mathrm{zcl}$ (bad weather conditions) and $\mathrm{zc} 2$ (natural disaster) from external factor group and r3 (ineffective planning and scheduling) from internal factor group.

The person distribution confirms the result from the summary statistics. The most agreeable respondent are C21 (located at +3.71 logits) and agreeable respondent is E27, D38 and D51, those are final year students and fresh graduates. The least agreeable expert is $\mathrm{d} 56$, located at the bottom of the person distribution at -0.33 logits. We noted in this section that the mean of the person distribution is higher than the mean of the item distribution. This indicates that all respondent involved in the content validity test tend to agree to the entire set of group factor and their items.

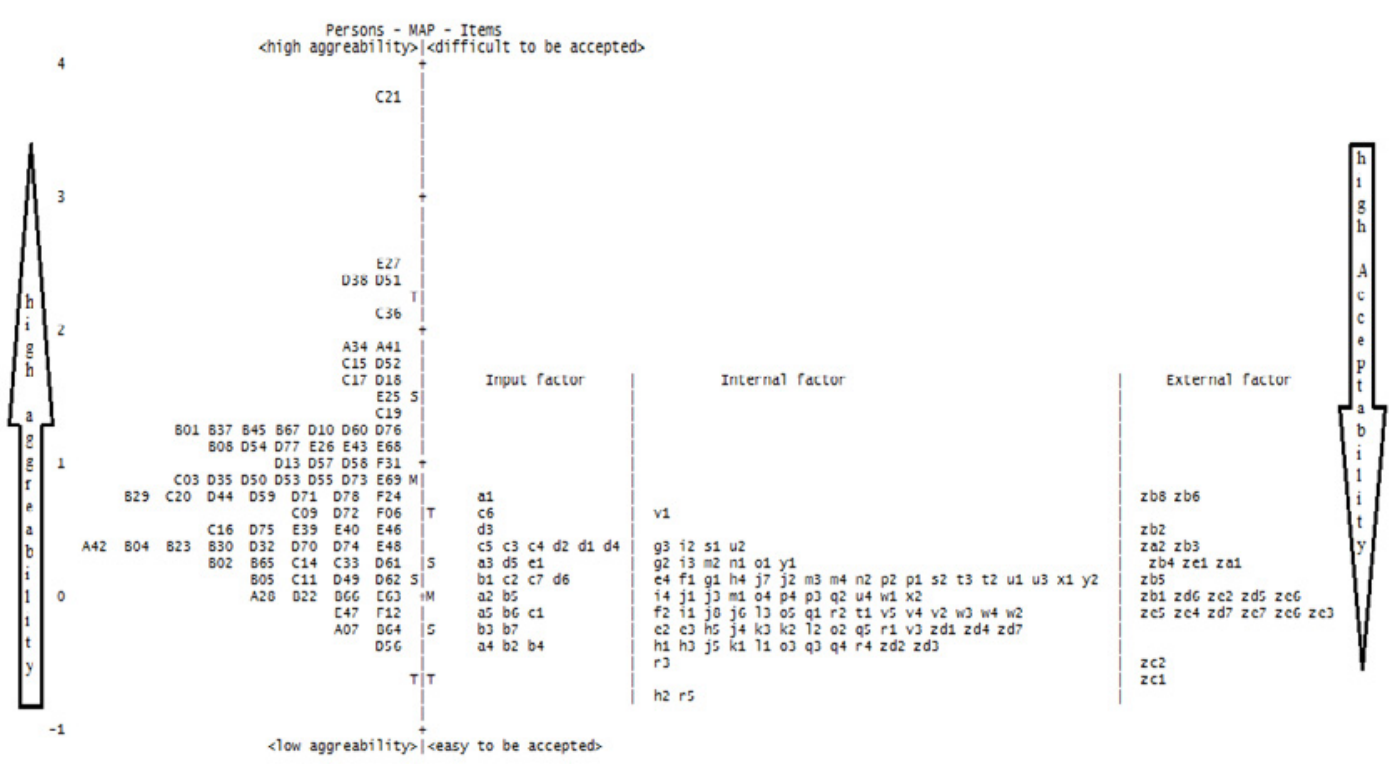

Figure 2: Person-Item Distribution Map (PIDM)

From the result above, the most influenced factor of delay are from the group of internal and external factors. The unrealistic project duration is the most critical factor of delay in this study, it is 
because the construction industry is often referred to as the industry that have a variety of risks and uncertainties compared to other industries [20]. A lots of unexpected and uncertainties event will affect the construction process so the construction time will become longer. The second most critical factor in this study is mistakes during construction. This item effected because of the factor can really affect the time of work and it will influence the next process of work [17] and may affect the time of construction.

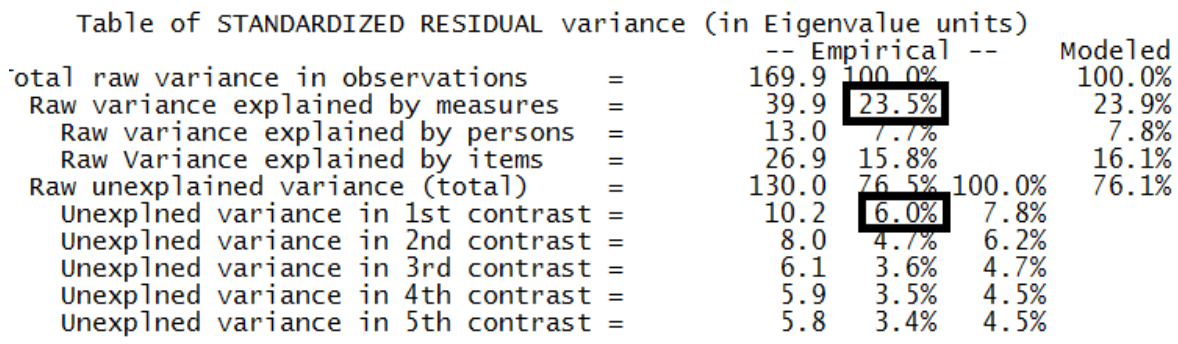

Figure 3: Principle contrast analysis

Figure 3 shows a segment of principal contrast analysis of Rasch residual variance. Variance explained by measures should be more and equal to $40 \%$ and unexplained variance in the first contrast should be less and equal to $15 \%$ [21]. The variance explained by measures is poor $(23.5 \%)$. The unidimensionality of the survey instrument is weak however it can be rechecking by a more-likely-tobe-good unexplained variance in the first contrast $(6.0 \%)$. Therefore the evidence of unidimensionality further supports the structural aspect of construct validity.

\section{Conclusion}

This pilot test confirmed that the causes of delay refined in the content validity test are acceptable. Its show that the theoretical framework developed is reliable to apply for construction delay research. As a result, researcher proposes that the owner of the project must plan the project wisely and should consider the unexpected event in the construction. Not only that experienced and well trained workers or labors should be provided by the contractor. This study does not establish the real model for causes of construction delay. Thus, for upcoming research, the questionnaire should be revising for further verification by experts in the construction industries. 


\begin{tabular}{|l|}
\hline \multicolumn{1}{|c|}{ INPUT FACTOR } \\
\hline \multicolumn{1}{|c|}{} \\
\hline LABOR \\
-Shortage of labors (d1) \\
-Personal conflicts among workers (d2) \\
- Strike (d3) \\
-High waiting time for availability of workers \\
-Unqualified workforce (d5) \\
-Low productivity level of labors (d6) \\
\hline MATERIALS \\
\hline -Shortages of materials on market (b1) \\
-Late delivery of material (b2) \\
-Receiving materials that do notfulfill project \\
requirements (b3) \\
-Changes in material types and specifications \\
during construction (b4) \\
-Defective materials provided (b5) \\
-Late submission of nominated materials (b6) \\
-Poor material procurement planning (b7) \\
\hline
\end{tabular}

\section{MOTIVATION}

-Ineffective delay penalties ( $s 1$ )

-Lack of incentives for contractor tofinish ahead of schedule (s2)

\section{TENDERING}

- Late contract award (g)

- High competition in bids ( $\mathrm{g} 2$ )

-Type of project bidding and award (g3)

\section{ADMINSTRATIVE}

- Owner interference (i1)

-Internal admin istrative problems (i2)

-Changes in management ways (i3)

-Undefined scope of working (i4)

\section{TEST AND INSPECTION}

-Insufficient inspectors (u1)

-Incapable inspectors (u2)

-Slow inspection of completed works by consultant (U3)

-Long waiting time for approval of tests and inspection (u4)

\section{LEGISTLATION}

-Legal disputes $\{x 1\}$

-Major disputes and negotiations ( $x 2$ )

\section{SCHEDULING AND CONTROLLING}

\section{TECHNIQUES}

Scheduling mismanagement ( $r 1)$

-Unrealistic project durations $(r 2$

-Ineffective planning and scheduling ( $r 3$ )

-Lack of program on works ( $r 4)$

- Improper Planning ( $r 5$ )

NTRUCTIONINDUSTRIES

\begin{tabular}{l|}
\hline \multicolumn{1}{|c|}{ INTERNAL FACTOR } \\
\hline COMMUNICATION \\
-Delay in instructions from consultants $(a 1)$ \\
-Lack of effective communication between parties $(a 2)$ \\
-Slow information flow between parties $(a 3)$ \\
-Dispute $(a 4)$
\end{tabular}

\section{OPERATION}

-Suspension of work (h1)

-Mistakes During Construction (h2)

-Delays in sub-contractors work (h3)

- Improper construction method (ha)

-Work interference between various contractors (h5)

\section{QUALITY}

-Tool many work on quality assurance/control $(\mathrm{y} 1)$ -Application of quality control based on foreign specification $(y 2)$

\section{VARIATIONS}

-Design changes by owner or his agent during

construction ( $q 1$

-Necessary variations by consultant ( $q 2$ )

-Changes of Design ( $q 3$ )

-Design Errors $(q 4)$

-Too many additional works (q5)

\section{DISCREPENCY}

-Mistakes and discrepancies in design documents (p1)

-Discrepancy between design specification and

building code $(p 2)$

- Unclear and inadequate details in drawings (p3)

-Mistakes and discrepancies incontract document (p4)

\section{PRE-INVESTIGATION}

-Insufficient data collection and survey before design -Mistakes with soil investigations (02)

-Foundation conditions encountered on site $(03)$

-Improper project feasibilitystudy $(04)$

-Inaccurate site investigation (05)

\section{SHOP DRAWING}

-Delay in preparation of shop drawings and sample materials (n1)

-Delay in approving shop drawings and sample materials $(\mathrm{n} 2)$

\section{EXPERIENCE}

-Lack of experience of consultant in construction projects ( $m 1)$

-Lack of experience of owner in construction projects -Lack of experience of contractor in construction projects $(\mathrm{m} 3)$

-Lack of experience of sub-contractor in construction projects $(m 4)$

\begin{tabular}{l}
\hline DESIGN \\
-Poor Design (v1) \\
-Complexity of project design ( $v 2$ ) \\
-Design errors made by designers due to unfamiliarity \\
with local conditions \& environment ( $v 3$ ) \\
-Late in revising and approving designdocuments by \\
owner (v4) \\
-Underestimation of complexity of projects / Project \\
complexity (v5)
\end{tabular}

\section{MANAGEMENT}

-Late issuing of approval documents $(\mathrm{j} 1)$

-Late documentation (j2)

-Inaccurate bills of quantities (j3)

-Poor professional management $(j 4)$

-Poor project management consultant (j5)

-Resourse management (j6)

-Poor contract management $(j 7)$

-Work approval by architect (j8)

\begin{tabular}{|l|}
\hline \multicolumn{1}{|c|}{ EXTERNAL FACTOR } \\
\hline
\end{tabular}

\section{SITE MANAGEMENT}

-Poor site management ( $k 1$ )

-Lack of coordination among project (k2)

-Delay in site mobilization ( $k 3$ )

\section{MONITORING}

-Poor supervision by contractor (I1)

- Poor site management by consultant (12)

-Poor supervision by architect (13)

\section{DRAWING}

-Accepting inadequate design

drawings consultant (w1)

-Delay in approval of drawing (w2)

-Delay in preparation of drawing by

consultant ( $w 3$ )

-Architect changes in drawings $\{w 4\}$

\section{SAFETY}

-Accidents during construction ( $t 1$ )

-Imbalance in the risk allocation ( $t 2$

-Lack of Application of safety aspect ( $t 3$ )

\section{DECISION MAKING}

-Slow decision making by owner (f1)

Slow decision making by project

management group ( $\mathrm{f2}$ )

Figure 4: List of causes of construction delay based on productivity factor 


\section{References}

1. E. Williams, "The Power of Engineering and Managment.," Department of Engineering Science News , University of Oxford, p. 3, 2012.

2. Wan Abdul Aziz bin Wan Abdullah, "Peranan kerajaan dalam dasar pembangunan negara," 2004.

3. N. W. Alnaser and R. Flanagan, "The need of sustainable buildings construction in the Kingdom of Bahrain,” Build. Environ., vol. 42, no. 1, pp. 495-506, Jan. 2007.

4. W. Menesi, "Construction Delay Analysis under Multiple Baseline Updates," University of Waterloo, Ontario, Canada, 2007.

5. N. Braimah, "An Investigation Into the use of Construction Delay and Disruption Analysis Methodologies," University of Wolverhampton, 2008.

6. S. M. Ahmed, S. Azhar, P. Kappagantula, and D. Gollapudi, "Delays in Construction A Brief Study of the Florida Construction Industry," in Proceedings of the 39th Annual Conference Clemson University, 2003, pp. 257-266.

7. Dayang Sabarian Safri, "A Comparative Study of Construction Project Delays in Johor and Sabah Region," Universiti Teknologi Malaysia, Johor Baharu, 2009.

8. D. J. Greenwood, A. N. Osborne, and M. A. Aggiag, "A comparative analysis of administrative delays in hospital buildings," in 17th Annual ARCOM Conference, 5, 2001, vol. 1, no. September, pp. 795-802.

9. J.-B. Yang, C.-C. Yang, and C.-K. Kao, "Evaluating schedule delay causes for private participating public construction works under the Build-Operate-Transfer model," Int. J. Proj. Manag., vol. 28, no. 6, pp. 569-579, Aug. 2010.

10. A. W. Shaikh, M. R. Muree, and A. S. Soomro, "Identification of Critical Delay Factors in Construction," Sindh Univ. Res. Jour, vol. 42, no. 2, pp. 11-14, 2010.

11. Mahamid and S. Arabia, "Common Risks Affecting Time Overrun in Road Construction Projects in Palestine : Contractors 'Perspective,” Australas. J. Constr. Econ. Build. this, vol. 13, no. 2, pp. 45-53, 2011.

12. R.-K. T. M. Akogbe, X. Feng, and J. Zhou, "Importance and ranking evaluation of delay factors for development construction projects in Benin,” KSCE J. Civ. Eng., vol. 17, no. 6, pp. 12131222, Aug. 2013.

13. G. Sweis, R. Sweis, a. Abu Hammad, and a. Shboul, "Delays in construction projects: The case of Jordan,” Int. J. Proj. Manag., vol. 26, no. 6, pp. 665-674, Aug. 2008.

14. F. J. Drewin, Construction Productivity. New York: Elsevier Science Publishing, 1982, p. 4.

15. M. E. Shehata and K. M. El-Gohary, "Towards improving construction labor productivity and projects' performance," Alexandria Eng. J., vol. 50, no. 4, pp. 321-330, Dec. 2011.

16. E. M. Rojas and P. Aramvareekul, "Is Construction Labor Productivity Really Declining?," J. Constr. Eng. Manag., no. February, pp. 41-46, 2003.

17. N. Hamzah, M. A. Khoiry, I. Arshad, W. H. W. Badaruzzaman, and N. M. Tawil, "Identification of the causes of construction delay in Malaysia," in World Academy of Science, Engineering and Technology, 2012, vol. 72, pp. 312-317.

18. J. Yang, K. Huang, C. Lee, and S. Chen, "Delay Impact Analysis Method for Lost Productivity In Construction Projects," pp. 953-954.

19. A. Soekiman, K. S. Pribadi, B. W. Soemardi, and R. D. Wirahadikusumah, "Factors Relating to Labor Productivity Affecting the Project Schedule Performance in Indonesia," in The Twelfth East Asia-Pacific Conference on Structural Engineering and Construction, 2011, vol. 14, pp. 865873. 
20. N. K. Acharya, Y. D. Lee, S. Y. Kim, J. C. Lee, and C. S. Kim, “Analysis of Construction Delay Factor: A Korean Perspective," in Proceedings of the 7th Asia Pacific Industrial Engineering and Management Systems Conference, 2006, no. December, pp. 883-895.

21. Z. M. Zain, A. Azim, A. Ghani, R. Abdullah, and R. Atan, "Blog Quality Measurement : Analysis of Criteria using The Rasch Model,” Int. J. New Comput. Archit. Their Appl., vol. 1, no. 3, pp. 665-682, 2011. 